\title{
Anion-dependent assembly of diverse 1D-3D silver(I) coordination networks with a thioether ligand
}

\author{
Hangxing Xiong, ${ }^{\mathrm{a}} \mathrm{Li} \mathrm{Li},{ }^{\mathrm{a}}$ E Liu, ${ }^{\mathrm{a}}$ Chengxiong Yang, ${ }^{\mathrm{a}}$ Yuan Zhuo Zhang, ${ }^{\mathrm{b}}$ James C. Fettinger ${ }^{\mathrm{c}}$ and \\ Guoqi Zhang ${ }^{\mathrm{b} *}$ \\ ${ }^{a}$ College of Chemical Engineering and Pharmacy, Jingchu University of Technology, Jingmen 448000, China \\ ${ }^{b}$ Department of Sciences, John Jay College and The Graduate Center, The City University of New York, \\ New York, NY 10019, USA \\ ${ }^{c}$ Department of Chemistry, University of California Davis, Davis, CA 95616, USA \\ *Corresponding author. Email address: guzhang@jjay.cuny.edu
}

Keywords: Thioether; Silver; Anion effect; Coordination network; Crystal structure

\begin{abstract}
A flexible thioether ligand, 1,3-bis(methylthiomethyl)benzene (L) has been employed to prepare supramolecular assemblies with silver salts of various anions such as $\mathrm{NO}_{3}^{-}$, $\mathrm{BF}_{4}^{-}, \mathrm{PF}_{6}^{-}$and $\mathrm{SbF}_{6}^{-}$. X-ray structural analysis reveals that even though the same metal ion $\left(\mathrm{Ag}^{+}\right)$and ligand $(\mathrm{L})$ were used to react under the same conditions, anions have played a critical role in driving the variation of metal-ligand binding modes as well as network topologies of the resultant coordination polymers. The reaction of $\mathrm{L}$ with silver nitrate resulted in a 2-D coordination network 1, composed of metallomacrocycles bridged with $\mathrm{NO}_{3}{ }^{-}$ions. A 3-D framework 2 was observed when silver tetrafluoroborate was used. Although $\mathrm{BF}_{4}^{-}$ions were not involved in coordinating with metal centers, the participation of water molecules led to a different metal-ligand binding mode and hence the formation of a network with higher dimension. The large, non-coordinating anion $\mathrm{PF}_{6}{ }^{-}$was found to be responsible for the assembly of a 2-D grid-like network 3 , in which interesting $4+4$ metallocycles occupied with $\mathrm{PF}_{6}{ }^{-}$ions were disclosed. However, the presence of a larger anion
\end{abstract}


analogue, $\mathrm{SbF}_{6}^{-}$simplified the network structure to a 1-D helical chain (4) through the coordination of solvent molecules $\left(\mathrm{CH}_{3} \mathrm{CN}\right)$ with silver(I) centers.

\section{Introduction}

The structural topology and dimensionality of metal-organic coordination networks play a key role in regulating their physical and materials properties [1, 2]. In this regard, the rational design of network structures through judicious selection of metal sources and organic ligands has been the center of recent research efforts in order to fabricate materials with desired properties and functionality [3]. While the variation of both organic ligands and metal cations was believed to determine the formation of diverse coordination complexes or networks of one- to three-dimensions (1-3D), other factors including counter anions, solvents and reaction conditions have also great impact on the structural diversity of the resultant metal-organic coordination architectures [4]. Amongst those, the role of anions in governing the self-assembly process of metals and organic ligands, and hence the supermolecular structures of coordination assemblies has been highlighted in recent reports [5].

Whereas tremendous research efforts in metallosupramolecular and metal-organic materials chemistry have concerned the employment of nitrogen- and oxygen-donor ligands (typically polypyridine and carboxylate compounds) [6], sulfur-containing ligands remain less explored, probably owing to both their weak coordination ability with most transition metals and their poor thermal- and air-stability [7]. To date, several types of macrocyclic and acyclic thioethers have been investigated for the construction of network solids with metal ions, and preferably silver ion has been popularly selected as a soft Lewis acid for sulfur coordination in these studies [8]. In

addition, $\mathrm{Ag}^{\mathrm{I}}$ complexes proved to be attractive to chemists owing to their widespread applications in many aspects including photoluminescence materials, sensors, biochemistry and catalysis [9]. However, the coordination versatility between thioether ligands and silver ions has been not fully explored, despite interesting coordination modes and unique structural features have been observed in some known silverthioether complexes/networks $[10,11]$. 
To extend our understanding on the silver(I) coordination chemistry of thioethers, we focus on an acyclic bidentate thioether ligand, 1,3-bis(methylthiomethyl)benzene (L), which adopts three types of ligand conformations while coordinating with metals (Scheme 1), and herein wish to report on the versatile self-assembly of this ligand with various silver(I) salts. It is revealed that new, diverse silver-thioether coordination networks could be attained based upon the use of different silver salts, and the counter anions $\left(\mathrm{NO}_{3}{ }^{-}, \mathrm{BF}_{4}^{-}, \mathrm{PF}_{6}^{-}\right.$and $\left.\mathrm{SbF}_{6}^{-}\right)$were found to significantly affect the coordination modes (Scheme 2) and hence the supramolecular structures of the products.

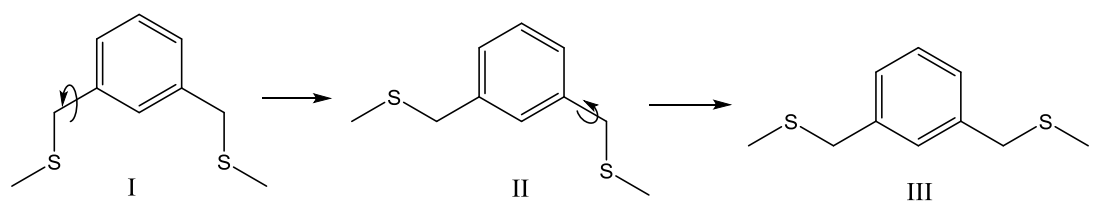

Scheme 1. Three possible conformations (from I to III) of ligand L resulting from the rotation about the indicated C-C single bonds.

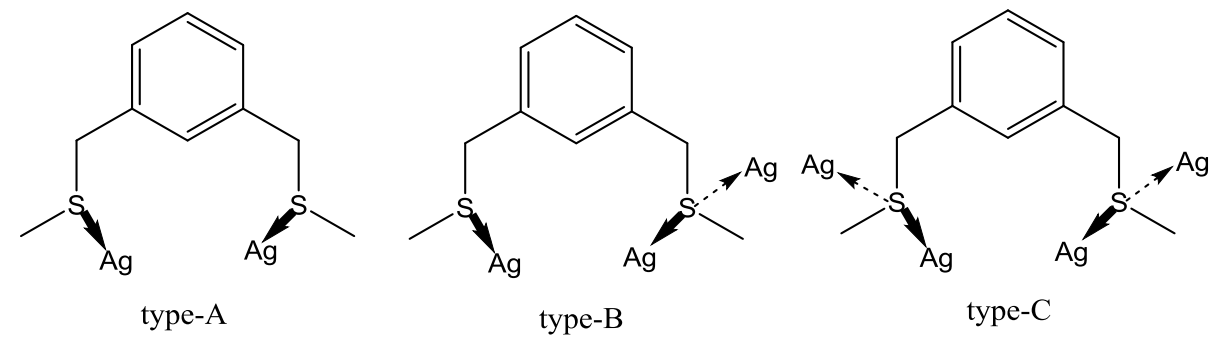

Scheme 2. Possible coordination modes of ligand L (based on conformation I, Scheme 1) with silver(I) ions.

\section{Experimental}

\subsection{General}

Solvents and reagents were purchased from Fisher Scientific or Sigma-Aldrich in the US. All reactions were performed under ambient conditions (no inert atmosphere). FT-IR spectra were measured on a Shimadzu 8400 S instrument with solid samples using a Golden Gate ATR accessory. Thermogravimetric analysis (TGA) was carried out on a Shimadzu TG-50 analyzer under $\mathrm{N}_{2}$ atmosphere with a heating rate of $20^{\circ} \mathrm{C} / \mathrm{min} .{ }^{1} \mathrm{H}$ NMR spectrum was obtained at room temperature on a Bruker III $500 \mathrm{MHz}$ spectrometer with TMS as an internal 
standard. Elemental Analyses were performed by Midwest Microlab LLC in Indianapolis. Ligand L was synthesized according to a published procedure [12].

\subsection{Synthesis of $\mathrm{Ag}(\mathrm{L})\left(\mathrm{NO}_{3}\right)(\mathrm{1})$}

Ligand L (19.8 mg, $0.100 \mathrm{mmol})$ was dissolved in $\mathrm{CH}_{2} \mathrm{Cl}_{2}-\mathrm{MeCN}(10 \mathrm{~mL}, 1: 1$, v/v) in a 25 $\mathrm{mL}$ vial, to which an acetonitrile solution of $\mathrm{AgNO}_{3}(33.8 \mathrm{mg}, 0.200 \mathrm{mmol})$ was added upon stirring at room temperature. The resulting solution was allowed to stir for $30 \mathrm{~min}$ and then filtered. Slow evaporation of the filtrate over 5 days gave colorless crystals, which were suitable for X-ray diffraction analysis. The product was collected by decanting the solvent and then washed with diethyl ether, and dried in the air. Yield: $30.9 \mathrm{mg}$ (84\% based on L). FT-IR (solid, cm ${ }^{-1}$ ): 2921w, 1432m, 1405s, 1277s, 1155w, 1083w, 1023m, 990w, 908w, 815s, 730s, 669w, 599w. Anal. Calcd. for $\mathrm{C}_{10} \mathrm{H}_{14} \mathrm{AgNO}_{3} \mathrm{~S}_{2} \cdot 0.2 \mathrm{CH}_{2} \mathrm{Cl}_{2}$ : C 31.80, H 3.77, N 3.64\%. Found C 31.79, H 3.60, N 3.87\%.

\subsection{Synthesis of $\mathrm{Ag}_{2}(\mathrm{~L})\left(\mathrm{BF}_{4}\right)_{2} \cdot 0.25\left(\mathrm{H}_{2} \mathrm{O}\right)$ (2)}

The procedure was similar to that for 1, except for the replacement of $\mathrm{AgNO}_{3}$ with $\mathrm{AgBF}_{4}$ (38.8 mg, $0.200 \mathrm{mmol}$ ). After one week, colorless crystals of $\mathbf{2}$ were collected by filtration, washed with diethyl ether and dried in the air. Yield: $37.0 \mathrm{mg}(61 \%)$. FT-IR (solid, $\left.\mathrm{cm}^{-1}\right)$ : 3565br, 1627m, 1427m, 1288w, 1028s, 819m, 725s, 654w, 556m, 519m. Anal. Calcd. for $\mathrm{C}_{10} \mathrm{H}_{14} \mathrm{Ag}_{2} \mathrm{~B}_{2} \mathrm{~F}_{3} \mathrm{~S}_{2} \cdot 1.5 \mathrm{H}_{2} \mathrm{O}$ : C 19.54, H $2.79 \%$. Found C 19.16, H $2.82 \%$.

\subsection{Synthesis of $A g(L)_{2}\left(P F_{6}\right)(3)$}

The procedure is similar to that for $\mathbf{1}$, except for the replacement of $\mathrm{AgNO}_{3}$ with $\mathrm{AgPF}_{6}(50.4$ $\mathrm{mg}, 0.200 \mathrm{mmol}$ ). After one week, colorless crystals of $\mathbf{3}$ were collected by filtration, washed with diethyl ether and dried in the air. Yield: $27.5 \mathrm{mg}\left(85 \%\right.$ based on L). FT-IR ( $\left.\mathrm{solid}^{-1} \mathrm{~cm}^{-1}\right)$ : $1636 \mathrm{~m}, 1534 \mathrm{~m}, 1484 \mathrm{~m}, 1449 \mathrm{~s}, 1379 \mathrm{~s}, 1338 \mathrm{~s}, 1290 \mathrm{~s}, 1214 \mathrm{~m}, 1150 \mathrm{~m}, 1074 \mathrm{~m}, 1034 \mathrm{w}, 929 \mathrm{w}$, $839 \mathrm{w}, 779 \mathrm{~m}, 753 \mathrm{~m}, 601 \mathrm{~m}, 556 \mathrm{~m}$. Anal. Calcd. for $\mathrm{C}_{20} \mathrm{H}_{28} \mathrm{AgF}_{6} \mathrm{PS}_{4}$ : C 36.98, H 4.35; Found C $36.87, \mathrm{H} 4.24 \%$.

\subsection{Synthesis of $\mathrm{Ag}(\mathrm{L})\left(\mathrm{SbF}_{6}\right)\left(\mathrm{NCCH}_{3}\right)_{2}$ (4)}


The procedure is similar to that for $\mathbf{1}$, except for the replacement of $\mathrm{AgNO}_{3}$ with $\mathrm{AgSbF}_{6}$ ( $68.4 \mathrm{mg}, 0.200 \mathrm{mmol})$. After one week, colorless crystals of 4 were collected by filtration, washed with diethyl ether and dried in the air. Yield: $47.8 \mathrm{mg}$ (77\% based on L). FT-IR (solid, $\mathrm{cm}^{-1}$ ): 2929w, 2290m, 1484w, 1431s, 1326w, 1230w, 1162w, 1086w, 986m, 815s, 723s, 655s, 597w. Anal. Calcd. for $\mathrm{C}_{14} \mathrm{H}_{20} \mathrm{AgF}_{6} \mathrm{~N}_{2} \mathrm{~S}_{2} \mathrm{Sb}$ : C 26.94, H 3.23, N 4.49\%. Found C 27.12, H 3.44, N 4.39\%.

\subsection{X-ray Structural Determinations}

Suitable crystals of 1-4 were mounted on Cryoloops with Paratone-N oil. Data were collected with a Bruker APEX II CCD using Mo-K $\alpha$ radiation and corrected for absorption with SADABS and structures solved by direct methods. All non-hydrogen atoms were refined anisotropically by full-matrix least squares on $\mathrm{F}^{2}$. Hydrogen atoms were found from Fourier difference maps and refined isotropically, otherwise they were placed in calculated positions with appropriate riding parameters. Crystal structures and packing figures were drawn with the program Mercury v. 2.4 [13]. During the structural refinement of $\mathbf{2}$ it was found that the main structure possessed multiple disorders: $\operatorname{Ag}(2)$ was modelled as disordered over two sites (0.46:0.04); $\mathrm{O}(1)$ and $\mathrm{O}(2)$ were better refined while pushing off their special positions $(1 / 2$,

$3 / 4, \mathrm{z}$ ); The $\mathrm{BF}_{4}$ counterions were found to possess three or two orientations that overlap. For the triple disorder, $\mathrm{B}(11): \mathrm{B}(14): \mathrm{B}(17)$ has a ratio of $0.38: 0.38: 0.24$, and for the two position disorder, ratio of $\mathrm{B}(21): \mathrm{B}(24)$ was $0.5: 0.5$. In addition, a lone peak indicated the presence of an additional contributor that has been assigned as a very low occupancy ( $25 \%)$ water molecule, $\mathrm{O}(31)$, without its hydrogen atoms being located or calculated. All full occupancy non-hydrogen atoms were refined anisotropically. A variety of restraints have been implemented to idealize the $\mathrm{BF}_{4}$ groups, e.g. SIMU to restrain the thermal parameters, SADI to keep bond distances the same or nearly, and EADP to restrain atoms that are nearly overlapping to have the same thermal parameter.

Table 1. Structural Refinement Data for Compounds 1-4.

\begin{tabular}{lllll}
\hline Compound & $\mathbf{1}$ & $\mathbf{2}$ & $\mathbf{3}$ & $\mathbf{4}$ \\
\hline Formula & $\mathrm{C}_{10} \mathrm{H}_{14} \mathrm{AgNO}_{3} \mathrm{~S}_{2}$ & $\mathrm{C}_{10} \mathrm{H}_{14.5} \mathrm{Ag}_{2} \mathrm{~B}_{2} \mathrm{~F}_{8} \mathrm{O}_{1.25} \mathrm{~S}_{2}$ & $\mathrm{C}_{20} \mathrm{H}_{28} \mathrm{AgF}_{6} \mathrm{PS}_{4}$ & $\mathrm{C}_{14} \mathrm{H}_{20} \mathrm{AgF}_{6} \mathrm{~N}_{2} \mathrm{~S}_{2} \mathrm{Sb}$ \\
Formula Weight & 368.21 & 6008.20 & 649.50 & 624.06 \\
Crystal system & Orthorhombic & Orthorhombic & Monoclinic & Orthorhombic \\
Space group & $C \mathrm{mc}_{1}$ & $I \mathrm{mma}$ & $P 2_{1} / \mathrm{n}$ & $P 2_{1} 2_{1} 2_{1}$
\end{tabular}




\begin{tabular}{|c|c|c|c|c|}
\hline$a / \AA$ & $10.7296(8)$ & $20.888(3)$ & $16.8995(3)$ & $7.8651(13)$ \\
\hline$b / \AA$ & $15.3570(9)$ & $22.219(3)$ & $9.6474(2)$ & $10.2409(17)$ \\
\hline$c / \AA ̊$ & $7.6512(5)$ & $7.8466(10)$ & $17.0687(3)$ & $26.410(4)$ \\
\hline$\alpha /^{\circ}$ & 90 & 90 & 90 & 90 \\
\hline$\beta /^{\circ}$ & 90 & 90 & $112.6802(8)$ & 90 \\
\hline$\gamma /{ }^{\circ}$ & 90 & 90 & 90 & 90 \\
\hline$U / \AA^{3}$ & $1260.72(15)$ & $3641.6(8)$ & $2567.62(8)$ & $2127.2(6)$ \\
\hline$D_{c} / \mathrm{Mg} \mathrm{m}^{-3}$ & 1.940 & 2.219 & 1.680 & 1.949 \\
\hline$Z$ & 4 & 8 & 4 & 4 \\
\hline$\mu / \mathrm{mm}^{-1}$ & 1.924 & 2.455 & 1.224 & 2.438 \\
\hline$T / \mathrm{K}$ & $120(2)$ & $190(2)$ & $90(2)$ & $90(2)$ \\
\hline Reflections/Unique & $6274 / 1186$ & $16490 / 2303$ & $19797 / 5911$ & $25160 / 6514$ \\
\hline Parameters & 91 & 206 & 321 & 240 \\
\hline$R_{1}{ }^{\mathrm{a}}, w R_{2}{ }^{\mathrm{b}}[I>2 \sigma(I)]$ & $0.0153,0.0326$ & $0.0387,0.1030$ & $0.0183,0.0438$ & $0.0250,0.0555$ \\
\hline$R_{1}^{\mathrm{a}}, w R_{2}^{\mathrm{b}}$ (all data) & $0.0169,0.0331$ & $0.0406,0.1011$ & $0.0205,0.0448$ & $0.0258,0.0558$ \\
\hline GOF & 1.077 & 1.052 & 1.059 & 1.224 \\
\hline
\end{tabular}

${ }^{\mathrm{a}} R_{1}=\left(F_{\mathrm{o}}-F_{\mathrm{c}}\right) / F_{\mathrm{o}} \cdot{ }^{\mathrm{b}} w R_{2}=\left[w\left(F_{\mathrm{o}}{ }^{2}-F_{\mathrm{c}}{ }^{2}\right)^{2} / w\left(F_{\mathrm{o}}\right)^{2}\right]^{1 / 2}$

Table 2. Selected bond lengths $(\AA)$ and angles $\left({ }^{\circ}\right)$ for compounds 1-4.

\begin{tabular}{|c|c|c|c|}
\hline \multicolumn{4}{|l|}{1} \\
\hline $\mathrm{Ag}-\mathrm{S} 1$ & $2.5185(6)$ & $\mathrm{Ag}-\mathrm{S} 1^{\mathrm{a}}$ & $2.5186(6)$ \\
\hline $\mathrm{Ag}-\mathrm{O} 3$ & $2.357(3)$ & $\mathrm{Ag}-\mathrm{O} 3^{\mathrm{b}}$ & $2.533(3)$ \\
\hline $\mathrm{S} 1-\mathrm{C} 1$ & $1.808(2)$ & $\mathrm{S} 1-\mathrm{C} 2$ & $1.825(2)$ \\
\hline $\mathrm{O} 3-\mathrm{Ag} 1-\mathrm{S} 1$ & $117.45(3)$ & $\mathrm{S} 1-\mathrm{Ag} 1-\mathrm{S} 1^{\mathrm{a}}$ & $113.18(3)$ \\
\hline $\mathrm{O} 3-\mathrm{Ag} 1-\mathrm{O} 3^{\mathrm{b}}$ & $114.91(4)$ & $\mathrm{C} 1-\mathrm{S} 1-\mathrm{Ag} 1$ & $110.20(8)$ \\
\hline \multicolumn{4}{|l|}{2} \\
\hline Ag1-S1 & $2.4193(9)$ & Ag2-O2 & $2.334(5)$ \\
\hline Ag2-S1 & $2.5333(9)$ & $\mathrm{Ag} 2 \mathrm{~B}-\mathrm{S} 1$ & $2.562(3)$ \\
\hline $\mathrm{Ag} 2 \mathrm{~B}-\mathrm{O} 2$ & $2.356(7)$ & $\mathrm{S} 1-\mathrm{C} 1$ & $1.805(4)$ \\
\hline $\mathrm{S} 1-\mathrm{C} 2$ & $1.832(4)$ & Ag2-O1 & $2.634(5)$ \\
\hline $\mathrm{S} 1-\mathrm{Ag} 1-\mathrm{S} 1^{\mathrm{d}}$ & $172.10(4)$ & $\mathrm{O} 2-\mathrm{Ag} 2-\mathrm{S} 1$ & $129.58(18)$ \\
\hline $\mathrm{S} 1-\mathrm{Ag} 2^{\mathrm{c}}-\mathrm{S} 1^{\mathrm{c}}$ & $112.80(4)$ & Ag1-S1-Ag2 & $119.66(4)$ \\
\hline \multicolumn{4}{|l|}{3} \\
\hline Ag1-S1 & $2.5361(4)$ & Ag1-S2 & $2.5394(4)$ \\
\hline $\mathrm{Ag} 1-\mathrm{S} 9^{\mathrm{e}}$ & $2.5764(4)$ & Ag1-S $19^{f}$ & $2.5912(4)$ \\
\hline $\mathrm{S} 1-\mathrm{C} 1$ & $1.7921(17)$ & $\mathrm{S} 1-\mathrm{C} 2$ & $1.8202(14)$ \\
\hline $\mathrm{S} 2-\mathrm{C} 11$ & $1.8052(16)$ & $\mathrm{S} 2-\mathrm{C} 12$ & $1.8223(14)$ \\
\hline $\mathrm{S} 1-\mathrm{Ag} 1-\mathrm{S} 2$ & $118.303(12)$ & $\mathrm{S} 1-\mathrm{Ag} 1-\mathrm{S} 9^{\mathrm{e}}$ & $99.798(13)$ \\
\hline $\mathrm{S} 2-\mathrm{Ag} 1-\mathrm{S} 9^{\mathrm{e}}$ & $111.976(12)$ & $\mathrm{S} 1-\mathrm{Ag} 1-\mathrm{S} 19^{\mathrm{f}}$ & $105.842(12)$ \\
\hline $\mathrm{S} 2-\mathrm{Ag} 1-\mathrm{S} 19^{\mathrm{f}}$ & $103.781(12)$ & $S 9^{\mathrm{e}}-\mathrm{Ag} 1-\mathrm{S} 19^{\mathrm{f}}$ & $117.713(12)$ \\
\hline \multicolumn{4}{|l|}{4} \\
\hline $\mathrm{Ag} 1-\mathrm{S} 1$ & $2.4704(10)$ & $\mathrm{Ag} 1-\mathrm{S} 13^{\mathrm{g}}$ & $2.5098(10)$ \\
\hline Ag1-N1 & $2.402(4)$ & Ag1-N2 & $2.373(4)$ \\
\hline $\mathrm{N} 1-\mathrm{Ag} 1-\mathrm{N} 2$ & $90.96(15)$ & N1-Ag1-S1 & $104.53(12)$ \\
\hline $\mathrm{N} 2-\mathrm{Ag} 1-\mathrm{S} 1$ & $119.54(11)$ & $\mathrm{N} 2-\mathrm{Ag} 1-\mathrm{S} 13^{\mathrm{g}}$ & $95.28(10)$ \\
\hline $\mathrm{S} 1-\mathrm{Ag} 1-\mathrm{S} 13^{\mathrm{g}}$ & $135.73(3)$ & $\mathrm{N} 1-\mathrm{Ag} 1-\mathrm{S} 13^{\mathrm{g}}$ & $101.01(10)$ \\
\hline
\end{tabular}


Symmetry operations used to generate equivalent atoms: ${ }^{\mathrm{a}}-\mathrm{x}, \mathrm{y}, \mathrm{z} ;{ }^{\mathrm{b}}-\mathrm{x},-\mathrm{y}, \mathrm{z}+{ }^{1} \frac{1}{2} ;{ }^{\mathrm{c}} \mathrm{x},-\mathrm{y}-1 / \frac{1}{2}, \mathrm{z} ;{ }^{\mathrm{d}} \mathrm{x},-\mathrm{y},-\mathrm{z} ;{ }^{\mathrm{e}}-$ $\mathrm{x}+1 / 2, \mathrm{y}+1 / 2,-\mathrm{z}+1 / 2 ;{ }^{\mathrm{f}} \mathrm{x}-1 / 2,-\mathrm{y}-1 / 2, \mathrm{z}-1 / 2 ;{ }^{\mathrm{g}}-\mathrm{x}+1 / 2,-\mathrm{y}, \mathrm{z}+1 / 2$.

\section{Results and Discussion}

\subsection{Synthesis and characterization of $\mathrm{Ag}(\mathrm{L})\left(\mathrm{NO}_{3}\right)(1)$}

Whereas cyclic thioethers were more extensively explored, studies on the coordination chemistry of discrete, acyclic thioethers were limited. L was chosen in this work, owing to its diverse molecular conformations and coordination versatility to silver(I) (Schemes 1 and 2), and that the ability of this type of ligands to form network polymers with silver(I) has been previously demonstrated from its structural analogues [11].

The reaction of $\mathrm{L}$ with two equivalents of silver nitrate in a $\mathrm{CH}_{2} \mathrm{Cl}_{2}-\mathrm{MeCN}$ solution afforded after slow evaporation colorless crystals of $\mathbf{1}$ in high yield, that are suitable for Xray diffraction analysis. Elemental analysis data reveals an empirical formula of $\operatorname{Ag}(\mathrm{L}) \mathrm{NO}_{3}$, suggesting a 1:1 metal-to-ligand ratio in $\mathbf{1}$. $\mathbf{1}$ is poorly soluble in common solvents, and slightly soluble in dimethyl sulfoxide (DMSO). The ${ }^{1} \mathrm{H}$ NMR spectrum of $\mathbf{1}$ in DMSO- $d_{6}$ reveals only signals identical to those of the free ligand, indicating the decomposition of the complex in DMSO. In the IR spectrum of 1 a strong band at around $1405 \mathrm{~cm}^{-1}$ appeared due to the coordinated $\mathrm{NO}_{3}^{-}$ions. X-ray structural analysis confirmed the formation of a coordination network involving effective Ag-S binding in the solid state (Fig. 1). 1 crystallizes in the orthorhombic space group $C \mathrm{mc} 2_{1}$ and in the asymmetric unit there contains only one half of ligand L, one silver ion and nitrate anion, and the second half of $\mathrm{L}$ was generated by symmetry (operation code: -x, y, z). The Flack parameter of crystal $\mathbf{1}$ having a acentric space group was refined to be -0.01(2), indicating $\mathbf{1}$ crystallizes as an enantiopure form, although achiral ligand was used. It was noticed that as seen in Fig. 1a the ligand molecules in $\mathbf{1}$ adopt the conformation I and type-A binding mode with two silver(I) centers

related by a $C_{2}$ symmetric axis (Schemes 1 and 2). Relevant bond parameters around metal centers are summarized in Table 2. The silver(I) center is tetracoordinate with two sulfur atoms from symmetry-related ligands and two oxygen atoms of the bridging nitrate ions, being in a slightly distorted tetrahedral environment. The Ag-S bond distances are almost identical (2.5185(6) and 2.5186(6) $\AA$, respectively), falling in the range of Ag-S bond lengths reported in the literature [11], yet the Ag-O bonds are slightly different in length (2.357(3) 
and 2.533(3) ^). Propagation of the repeat structure unit along the silver(II) centers results in the formation of an infinite 2-D coordination network which is composed of 20-membered macrocycles containing two ligand units, two silver(I) centers and two bridging nitrato-O atoms (Fig. 1b and 1c). In each macrocycle, the Ag...Ag nonbonding distance between two silver(I) centers bonded to the same ligand is approximately $10.7 \AA$, while the O-bridged Ag...Ag nonbonding distance is approximately 4.6 $\AA$. The two phenyl rings of ligands in the macrocycle are arranged in an edge-to-face fashion and thus effective C-H... $\pi$ interaction is observed between the rings. The C-H... $\pi$ (centroid) distance as illustrated in Fig. 1c is as short as ca. $2.85 \AA$ (Fig. 1c). It is worth mentioning that previously a silver(I) perchlorate complex based on a similar thioether ligand, 1,3-bis(phenylthiomethyl)benzene has been reported, where a structurally related grid-like network was observed [11a]. However, the structure of the repeating macrocyclic motif in this network is essentially distinct with that of 1. In the structure reported previously [11a], the silver centers are bridged by two oxygen atoms of the perchlorate anion, and the Ag-O bond distances are relatively longer (2.556(10) and 2.719(4) $\AA$, respectively), indicating weaker bonding interactions. In addition, the phenyl rings in the macrocycle are arranged in a face-to-face mode by $\pi . . \pi$ stacking interaction (the distance between two aromatic planes is ca. $3.5 \AA$ ), in sharp contrast to the C-H... interactions found in $\mathbf{1}$ (Fig. 1c)

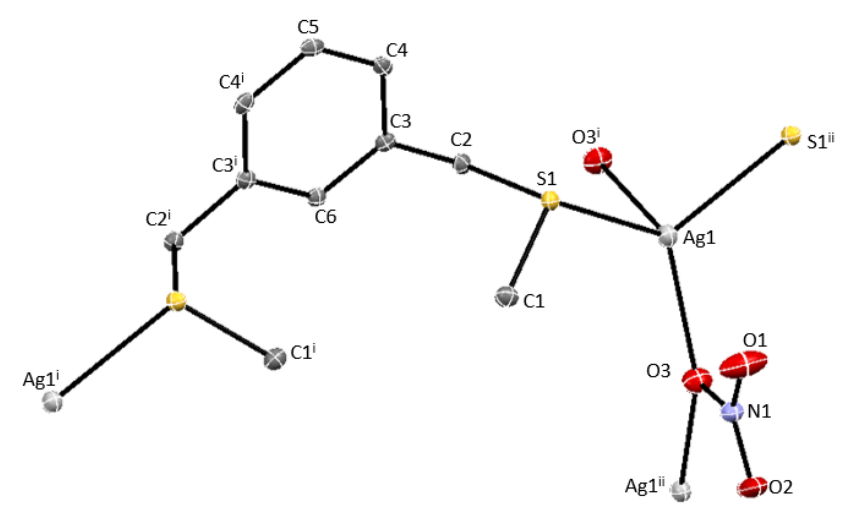

(a) 


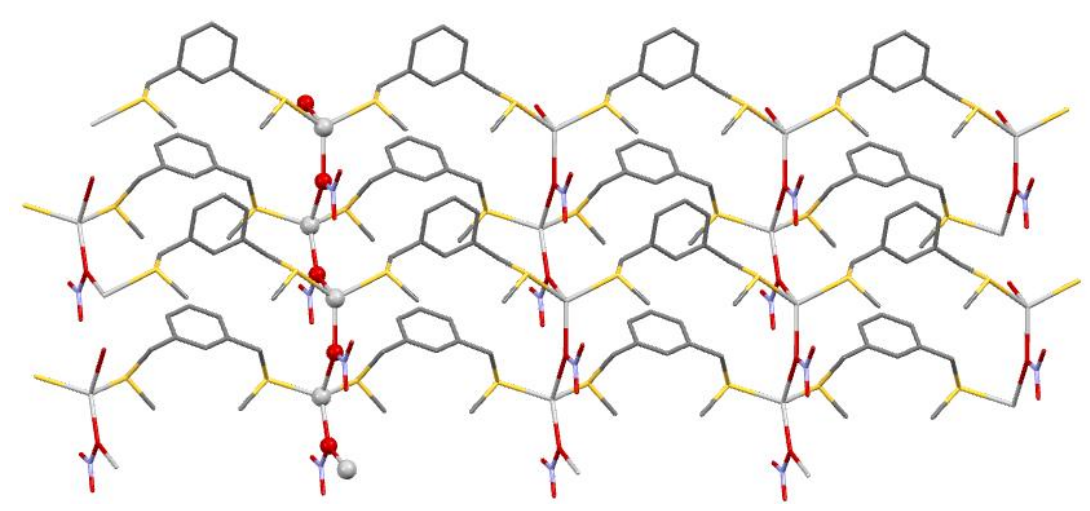

(b)

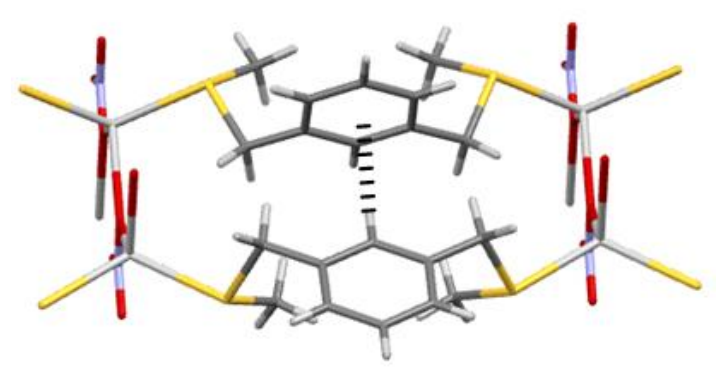

(c)

Fig. 1. (a) The ORTEP representation of crystal structure of $\mathbf{1}$ with thermal ellipsoid at $30 \%$ probability level. $\mathrm{H}$ atoms are omitted for clarity (b) The 2-D network found in $\mathbf{1}$ (an O-Ag-O chain is highlighted by ball-stick representation). (c) The 20-membered macrocycles composed of four silver(I) centers showing aromatic C-H... $\pi$ contact.

\subsection{Synthesis and characterization of $\mathrm{Ag}_{2}(\mathrm{~L})\left(\mathrm{BF}_{4}\right)_{2} \cdot 0.25\left(\mathrm{H}_{2} \mathrm{O}\right)$ (2)}

The critical role played by the counter anion (nitrate ion) in bridging the silver(I) center to form the 2-D network in $\mathbf{1}$ encouraged us to investigate the impact of other silver salts on the self-assembly process. We next examined the reaction between $\mathrm{L}$ and silver tetrafluoroborate under the same conditions as for $\mathbf{1}$, and colorless crystals of $\mathbf{2}$ were obtained in moderate yield. IR spectrum of 2 shows strong absorption as a broad band at around $3565 \mathrm{~cm}^{-1}$, indicating the presence of water molecules. In addition, peaks appear at ca. 1028 and $519 \mathrm{~cm}^{-}$ ${ }^{1}$, consistent with the inclusion of $\mathrm{BF}_{4}^{-}$in the coordination compound. X-ray structural analysis identifies the main silver(I) network in the solid state, although several disorders were found (see section 2.6 for details). 2 crystallizes in the orthorhombic space group Imma and the asymmetric unit contains only one half of the ligand molecule. Unlike the case in $\mathbf{1}$, two independent silver(I) centers that bind to the same sulfur atom through a $\mu_{2}-\mathrm{S}$ bridging 
coordination are observed in the asymmetric unit of 2 (Fig. 2a). The silver binding mode resembles the type-C mode in Scheme 2, whereas the ligand belongs to the conformation II (Scheme 1). Ag1 is two-coordinate with two symmetry-related sulfur atoms from distinct ligands and adopts an almost linear geometry (the S-Ag1-S angle is $\left.172.12(4)^{\circ}\right)$. In contrast, $\mathrm{Ag} 2$ is tetra-coordinate with not only two symmetry-related sulfur atoms, but also oxygen atoms from two water molecules that were involved in the structure of $\mathbf{2}$ during the reaction through a bis- $\mu_{2}-\mathrm{O}$ bridging mode. The counter anions $\mathrm{BF}_{4}^{-}$that are, as expected, noncoordinated exist in the lattice. Thus, the coordination chemistry and the extended supramolecular structure in $\mathbf{2}$ are completely different from that in $\mathbf{1}$, highlighting the drastic influence of counter anions.

In 2, the Ag1-S1 bond is slightly shorter than that found in 1 (2.4193(9) vs. 2.5185(6) $\AA$ ), despite that Ag2-S and Ag2B-S bond lengths (2.5332(9) and 2.562(3) $\AA$, respectively) are similar to those in $\mathbf{1}$. Owing to the more complicated connectivity between the thioether ligands and silver(I) centers, bond expansion of the asymmetric unit in 2 leads to the formation of a network with higher dimensionality (Fig. 2b and 2c). First of all, a macrocyle composed of two ligand molecules and two $\mathrm{Ag}_{2} \mathrm{O}_{2}$ cores is formed, whose structure is somehow close to that disclosed in $\mathbf{1}$. Propagation of the macrocycles through ligand $\mathrm{L}$ results in an infinite 1-D structure that involves only Ag2 centers. Further expansion through the Ag1 cores and more ligand molecules towards two directions of the 1-D assembly affords a 3-D metal-organic framework in which up to nanoscale cavities are present. $\mathrm{The}^{-\mathrm{BF}_{4}}$ counter anions occupy some of the larger cavities (Fig. 2c). It should be noted that although $\mathrm{BF}_{4}^{-}$ion did not participate in coordination with silver(I), both ligand conformation and binding mode have been affected by the existence of this anion during the reaction. In addition, the involvement of water molecules in the coordination event is also a key to the formation of framework of $\mathbf{2}$ having a higher dimension. The 3D topological presentation of 2 was generated by using TOPOS analysis [14] which suggests the 3D network could be better described as a uninodal $\left\{6^{\wedge} 6\right\}$ net (Fig. 2d) [15]. 


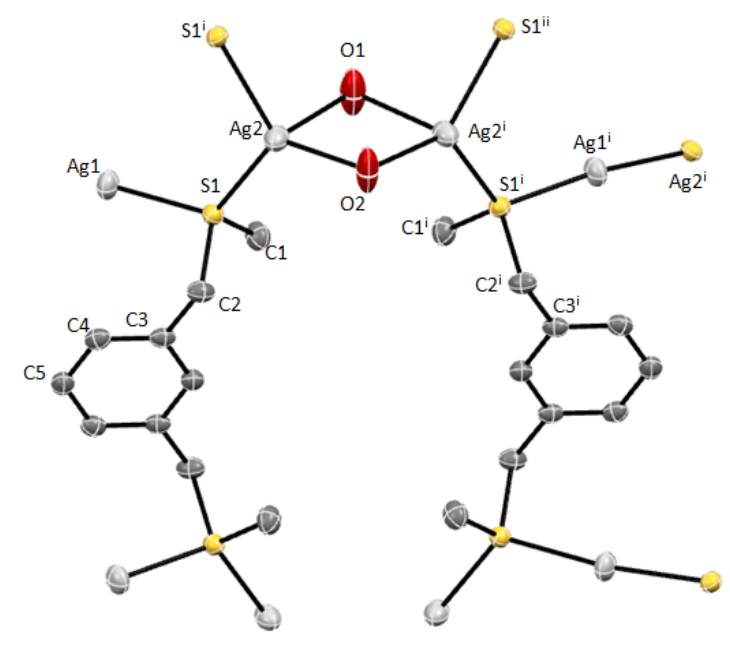

(a)

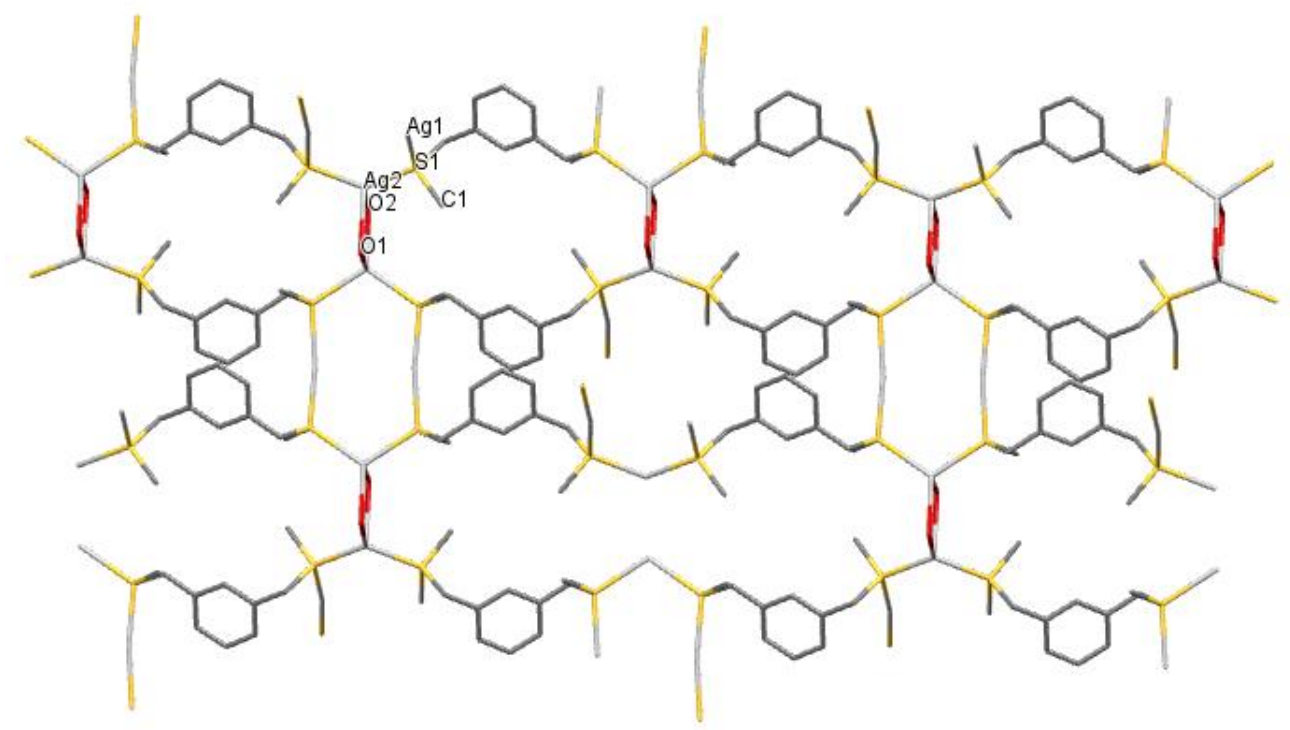

(b) 


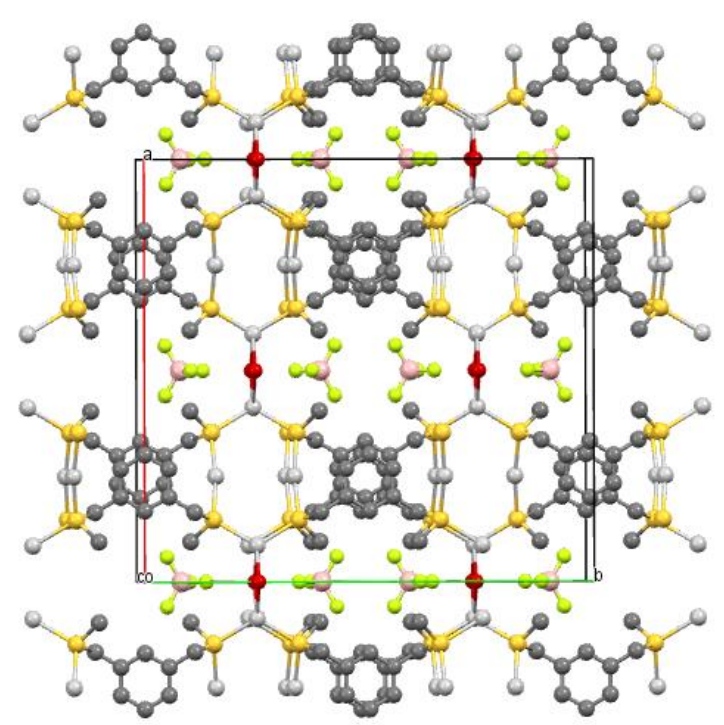

(c)

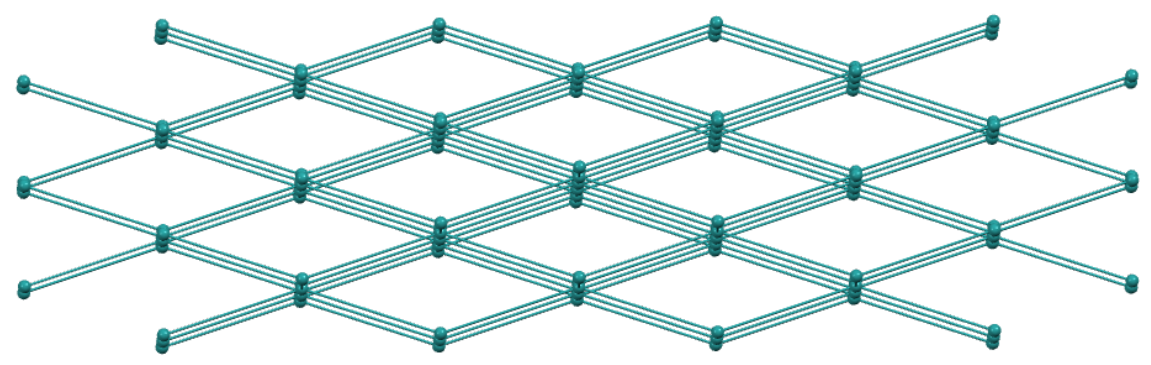

(d)

Fig. 2. (a) The ORTEP representation of partial structure of 2 with thermal ellipsoid at $30 \%$ probability level. $\mathrm{H}$ atoms are omitted for clarity. (b) The 2-D coordination network revealed in 2. (c) The 3-D framework found in 2 viewing down the crystallographic $c$ axis. (d) A TOPOS representation of $\mathbf{2}$ showing a uninodal $\left\{6^{\wedge} 6\right\}$ net.

\subsection{Synthesis and characterization of $\operatorname{Ag}(L)_{2}\left(P F_{6}\right)(3)$}

Having disclosed the remarkable role the anions played in driving diverse supramolecular architectures, we further explored the anion effect on the $\mathrm{Ag}-\mathrm{L}$ coordination chemistry, and used a larger anion hexafluorophosphate $\left(\mathrm{PF}_{6}{ }^{-}\right)$for the reaction. Thus, the combination of $\mathrm{L}$ with 2.0 equiv. $\mathrm{AgPF}_{6}$ under the same conditions for $\mathbf{1}$ and $\mathbf{2}$ afforded colourless crystals of $\mathbf{3}$ that were characterized by IR, elemental analysis and X-ray crystallography. Elemental analysis of the bulk sample reveals a metal-to-ligand ratio of 1:2, apparently different from those of $\mathbf{1}$ and $\mathbf{2}$, indicating new coordination chemistry in crystals of $\mathbf{3}$. The presence of $\mathrm{PF}_{6}{ }^{-}$ion in the structure of $\mathbf{3}$ was confirmed by its IR spectrum showing characteristic stretching and bending at ca. 839 and $556 \mathrm{~cm}^{-1}$. Indeed, X-ray structural 
analysis confirmed the formation of a novel 2-D network structure in 3 (Fig. 3). 3 crystallizes in the monoclinic space group $P 2{ }_{1} / \mathrm{n}$ and in the asymmetric unit two independent ligand molecules are observed. In addition, one silver(I) center and one $\mathrm{PF}_{6}^{-}$ion are present (Fig. 3a). Interestingly, in 3 the silver(I) center adopts a $S_{4}$ coordination environment with a pseudo-tetrahedral geometry, different from that observed in $\mathbf{1}$ and 2. Each silver(I) ion is ligated via four sulfur donors from four distinct ligands and meanwhile each ligand binds to two silver(I) ions to form an infinite 2-D grid-like structure that constitutes of square $4+4$ metallomacrocycles (Fig. 3b and 3c). Two ligand molecules in the macrocycle of $\mathbf{3}$ adopt the same conformation I as shown in Scheme 1 and the metal binding belongs to the type-A pattern (Scheme 2). The $4+4$ grid has a dimension of ca. $9.5 \times 9.6 \AA^{2}$, and features a saddlelike shape. The two pairs of $\mathrm{Ag}$...Ag distances between two $\mathrm{Ag}(\mathrm{I})$ centers in the grid are 9.513 and $9.647 \AA$, respectively, and the four $\mathrm{Ag}(\mathrm{I})$ centers are well coplanar. One $\mathrm{PF}_{6}{ }^{-}$ion resides in the center of each saddle-shaped grid. Ag-S bond lengths in $\mathbf{3}$ are close to those in 1. Bond expansion along the four $\operatorname{Ag}(\mathrm{I})$ centers of the grid leads to the assembly of a 2-D cationic network running down the $a b$ direction, as shown in Fig. 3c. Again, the anion $\mathrm{PF}_{6}^{-}$, albeit non-coordinated, has governed the coordination and supramolecular assembly between silver(I) and L, and is completely responsible for the generation of the 2-D grid-like network in $\mathbf{3}$, in sharp contrast to the structures of $\mathbf{1}$ and $\mathbf{2}$.

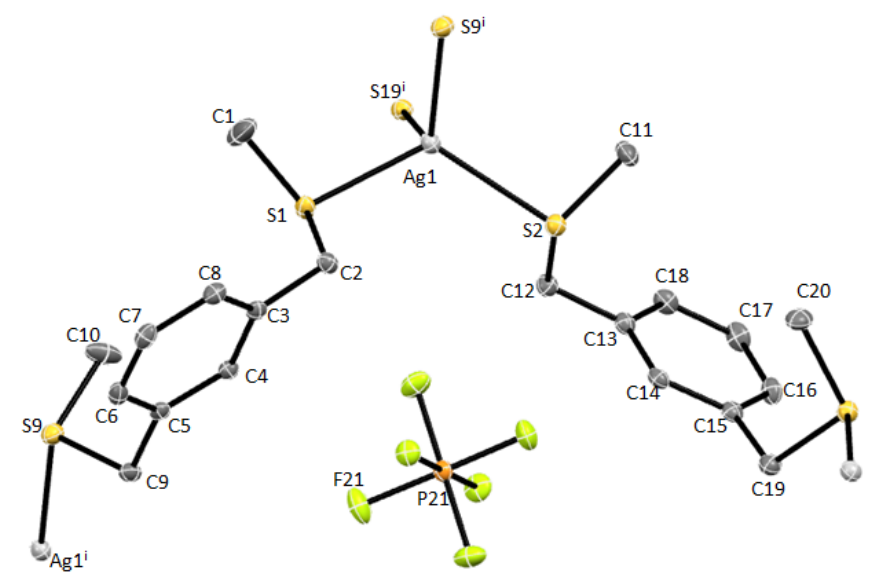

(a) 


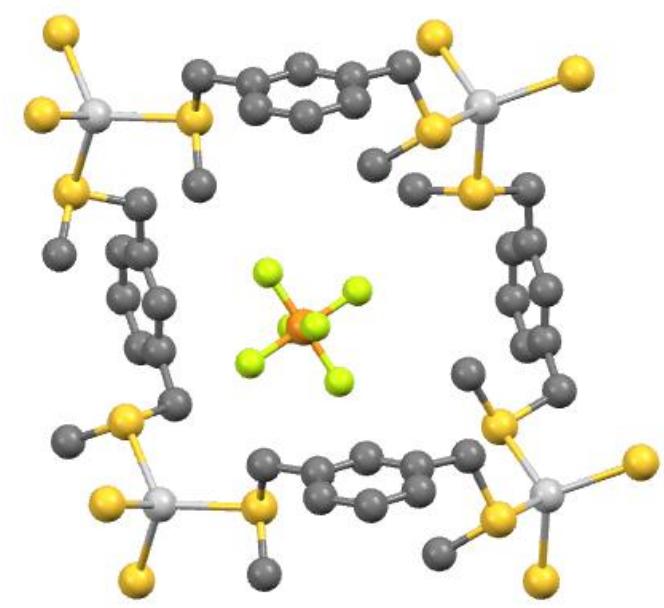

(b)

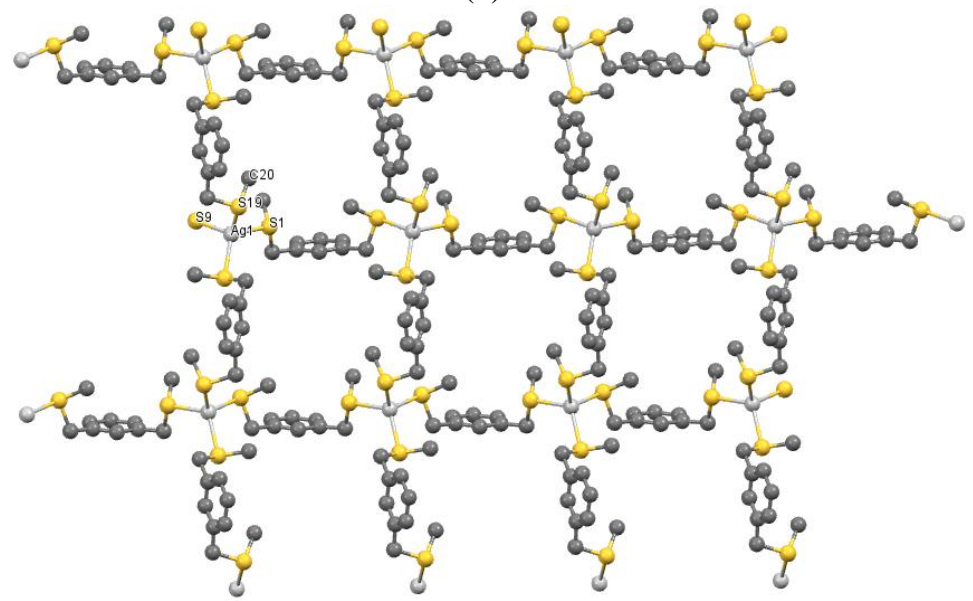

(c)

Fig. 3. (a) ORTEP representation of the repeating unit in the network of $\mathbf{3}$ with ellipsoids plotted at the $30 \%$ probability level. $\mathrm{H}$ atoms are omitted for clarity. (b) Ball-stick representation for one of the saddle-like grid containing a $\mathrm{PF}_{6}{ }^{-}$anion in the center. (c) Part of the 2-D grid-like network observed in 3 . $\mathrm{PF}_{6}{ }^{-}$anions are omitted for clarity.

\subsection{Synthesis and characterization of $\mathrm{Ag}(\mathrm{L})\left(\mathrm{SbF}_{6}\right)\left(\mathrm{NCCH}_{3}\right)_{2}$ (4)}

Encouraged by the above findings of remarkable anion induction effect, finally, we studied the reaction by replacing $\mathrm{PF}_{6}^{-}$with its analogue, a larger anion, hexafluoroantimonate $\left(\mathrm{SbF}_{6}^{-}\right)$. Accordingly, the same reaction conditions were applied and suitable crystals of $\mathbf{4}$ were obtained from the reaction of $\mathrm{L}$ with $\mathrm{AgSbF}_{6}$. The incorporation of acetonitrile molecules in the structure of $\mathbf{4}$ was confirmed by the IR absorption at around $2290 \mathrm{~cm}^{-1}$ and the strong peak at $556 \mathrm{~cm}^{-1}$ indicates the presence of $\mathrm{SbF}_{6}{ }^{-}$ions. Elemental analysis of bulk sample of $\mathbf{4}$ also suggests a 1:1 metal-ligand ratio. X-ray crystallographic studies reveal a 1-D polymeric chain, distinct from all the 
above described structures. 4 crystallizes in the orthorhombic system with a $P 2{ }_{1}{ }_{1} 2_{1}$ space group. Similar to 1, $\mathbf{4}$ also crystallizes as an enantiopure isomer, according to the Flack parameter that was refined to be $0.48(2)$. The asymmetric unit contains one independent ligand, one $\mathrm{Ag}^{+}$(accompanied ion with one $\mathrm{SbF}_{6}{ }^{-}$), and two coordinated $\mathrm{CH}_{3} \mathrm{CN}$ molecules (Fig. $4 \mathrm{a}$ ). Each $\mathrm{Ag}(\mathrm{I})$ is tetra-coordinate with two sulfur donors from two distinct ligands, and two nitrogen atoms from two $\mathrm{CH}_{3} \mathrm{CN}$ solvent molecules. Each ligand also coordinates with two symmetry-related $\mathrm{Ag}(\mathrm{I})$ centers. The $\mathrm{Ag}-\mathrm{S}$ bond lengths are unexceptional to those in $\mathbf{1 - 3}$, while the $\mathrm{S}-\mathrm{Ag}-\mathrm{S}$ angle is $135.73(3)^{\circ}$ and $\mathrm{N}-\mathrm{Ag}-\mathrm{N}$ angle is $90.96(15)^{\circ}$, severely deviated from a tetrahedral silver coordination sphere. The ligand molecule features the conformation II and the Ag-L binding is consistent with type-A coordination mode (Schemes 1 and 2). Extension of the repeating structural unit along the crystallographic $a$ axis results in the observation of an infinite 1-D polymeric chain (Fig. 4b), which is distinct with the 2- or 3-D networks as discussed above for 1-3. Interestingly, chains propagate along the crystallographic $a$ axis to form a helical structure and only $M$-helix was observed. This is consistent with the fact that the complex crystallizes in a chiral space group. The pitch of helix is approximately $7.87 \AA$, corresponding to the adjacent $\mathrm{Ag}$...Ag separation in the chain. Compared to $\mathbf{3}$, although similar anions were used, the lower dimensionality of 4 should be attributed to the coordination of solvent molecules $\left(\mathrm{CH}_{3} \mathrm{CN}\right)$ with silver(I), which prevents other ligands from accessing the silver(I) spheres and limits further dimensional expansion.

It is worth mentioning that although $\mathrm{L}$ has been previously employed as a pincer-type SCS ligand to construct various complexes with precious metals (such as $\mathrm{Pt}$ and $\mathrm{Pd}$ ) or silicon involving metal (or Si)-C bond formation [16], its silver(I) coordination chemistry observed here is essentially different. However, compared to relevant silver-thioether coordination complexes reported previously $[10,11,17]$, the Ag-S coordination modes involved in 1-4 are unexceptional. 


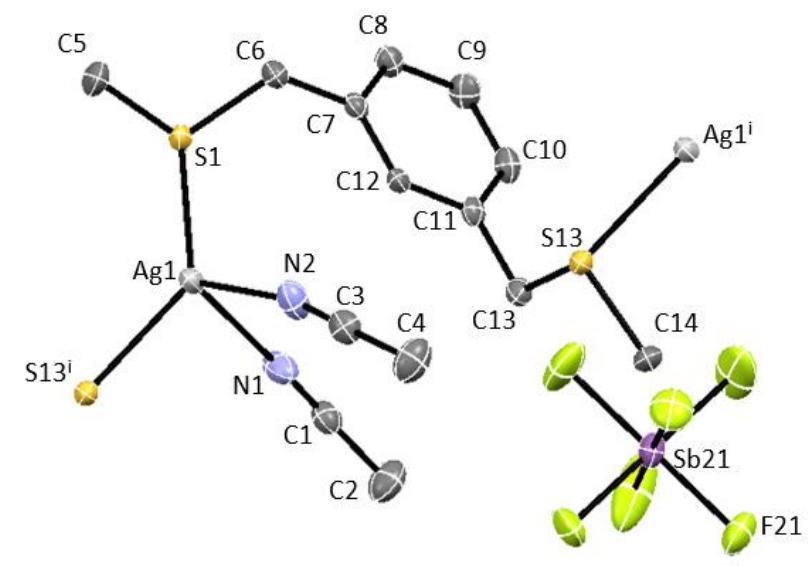

(a)

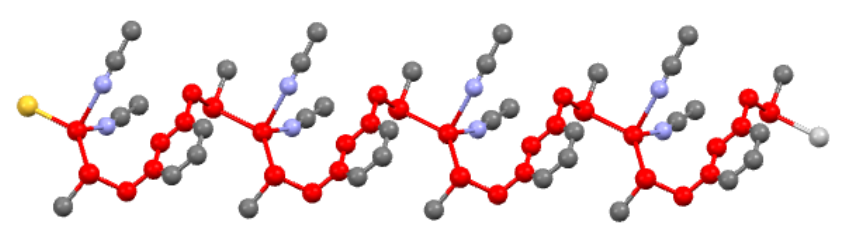

(b)

Fig. 4. (a) The repeat unit in the crystal structure of $\mathbf{4}$ with ellipsoids plotted at the $50 \%$ probability level. Hydrogen atoms are omitted for clarity. (b) The 1-D left-handed helical chain ( $M$-helix) found in the structure of $\mathbf{4}$, the helical chain is highlighted with red color.

\subsection{Thermal Properties}

Thermal stability of four silver(I) coordination compounds were examined by thermogravimetric analysis (TGA) under $\mathrm{N}_{2}$ atmosphere. The corresponding TG curves for 1-4 are presented in Fig. 5. As shown in Fig. 5, compound $\mathbf{1}$ is stable up to $179^{\circ} \mathrm{C}$ and then experiences decomposition in two stages $\left(179-365^{\circ} \mathrm{C}\right.$ and $\left.500-645^{\circ} \mathrm{C}\right)$ with a total weight loss of ca. $54.8 \%$, owing to the removal of ligand molecules from the complex (calcd. 54.0\%). Compound 2 undergoes a small weight loss (ca. 4.2\%) between $50-147^{\circ} \mathrm{C}$, accounting for the loss of water molecules from the $3 \mathrm{D}$ silver framework of 2 (ca. $1.5 \mathrm{H}_{2} \mathrm{O}$ per unit, calcd. 4.4\%), which is in agreement with the data of elemental analysis, indicating $\mathbf{2}$ is hygroscopic in the air. $\mathbf{2}$ is then decomposed upon heating to $196^{\circ} \mathrm{C}$ by removing the ligand molecules. Compound 3 proves to be less thermostable and begins to decompose gradually from $163{ }^{\circ} \mathrm{C}$. In contrast, 4 is stable up to $212^{\circ} \mathrm{C}$ at which temperature a slight weight loss (ca. 1.25\%) is observed, 
consistent with the removal of two coordinated $\mathrm{CH}_{3} \mathrm{CN}$ molecules per structural unit (calcd. 1.3\%). Again, upon further heating major decomposition of 4 occurs at $234{ }^{\circ} \mathrm{C}$.

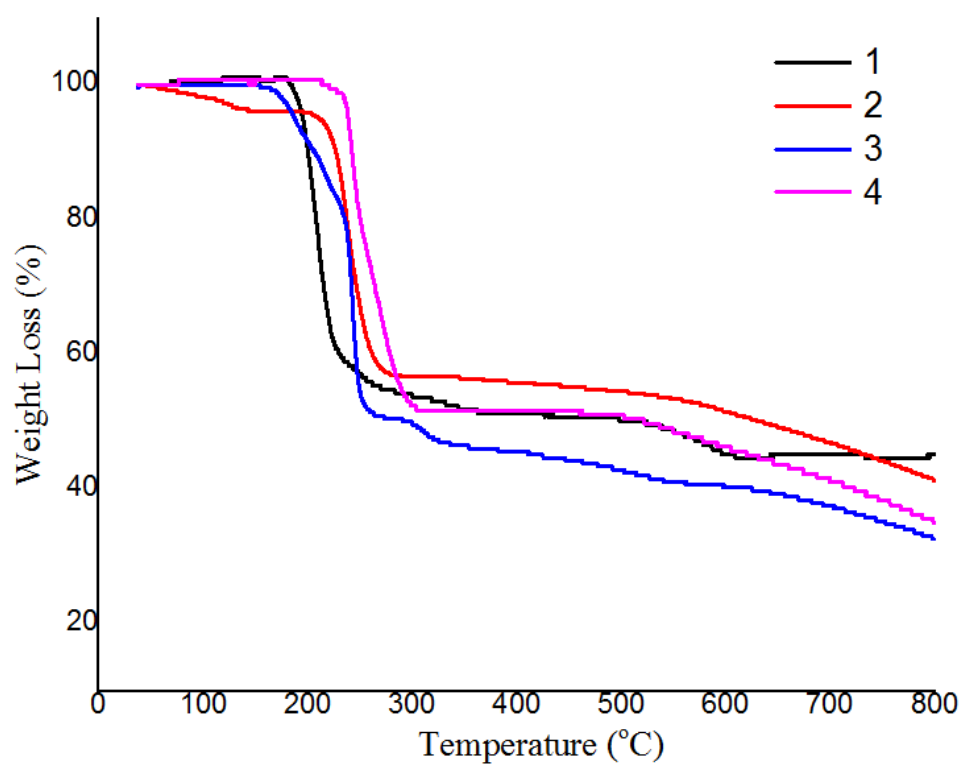

Fig. 5. The TG curves for complexes 1-4.

\section{Conclusions}

In conclusion, we have described the silver(I)-mediated assembly of four novel coordination polymers with diverse 1- to 3-D network structures based on a flexible thioether ligand, depending on the use of various anions in the silver salts. It was revealed that different counter anions $\left(\mathrm{NO}_{3}^{-}, \mathrm{BF}_{4}^{-}, \mathrm{PF}_{6}^{-}\right.$and $\left.\mathrm{SbF}_{6}^{-}\right)$have played critical roles in regulating the formation of distinct metal-organic architectures, although the same reaction conditions were applied. The structural diversity of 1- to 3-D networks observed in 1-4 highlights the effect of anion variation on the silver-thioether coordination networks. Further investigations are directed towards relevant coordination polymers of thioethers with different ligand backbones.

\section{Acknowledgements}

We are grateful to a PSC-CUNY award (\#69069-0047), A "Seed Grant" from the Office for Advanced Research at John Jay College and the Program for Research Initiatives for Science Majors (PRISM) funded by the Title V, HSI-STEM and MSEIP programs within the U.S. 
Department of Education; the PAESMEM program through the National Science Foundation; and New York State's Graduate Research and Teaching Initiative. The National Science Foundation (Grant 0840444) is acknowledged for the Dual source X-ray diffractometer. We thank Mr. Maximilian Klein (University of Basel) for the generation of Fig. 2d. The Natural Science Foundation of Hubei Province in China (2015CFA130 and 2013CFA015) is also acknowledged for partial support.

\section{References}

[1] (a) J.-M. Lehn, Supramolecular Chemistry: Concepts and Perspectives; VCH: Weinheim, Germany, 1995;

(b) F. Novio, J. Simmchen, N. V. Mera, L. A. Ferré, D. R. Molina, Coord. Chem. Rev., 257 (2013) 2839;

(c) J.H. Jung, J.H. Lee, J.R. Silverman, G. John, Chem. Soc. Rev., 42 (2013) 924;

(d) W.L. Leong and J.J. Vittal, Chem. Rev., 111 (2011) 688;

(e) G. Givaja, P.A. Ochoa, C.J.G. García, F. Zamora, Chem. Soc. Rev., 41 (2012) 115;

(f) Y.-Z. Zheng, Z. Zheng, X.-M. Chen, Coord. Chem. Rev. 258-259 (2014) 1.

[2] (a) A. Phan, C.J. Doonan, F.J. Uribe-Romo, C.B. Knobler, M.O’Keeffe, O.M. Yaghi, Acc. Chem. Res. 43 (2010) 58.

(b) N. Kornienko, Y. Zhao, C.S. Kley, C. Zhu, D. Kim, S. Lin, C.J. Chang, O.M. Yaghi, P. Yang, J. Am. Chem. Soc. 137 (2015) 14129.

(c) H.S. Cho, H. Deng, K. Miyasaka, Z. Dong, M. Cho, A.V. Neimark, J.K. Kang, O.M. Yaghi, O. Terasaki, Nature 527 (2015) 503.

[3] (a) K. Sumida, D.L. Rogow, J.A. Mason, T.M. McDonald, E.D. Bloch, Z.R. Herm, T.H. Bae, J.R. Long, Chem. Rev. 112 (2012) 933;

(b) C.S. Hawes, Y. Nolvachai, C. Kulsing, G.P. Knowles, A.L. Chaffee, P.J. Marriott, S.R. Batten, D.R. Turner, Chem. Commun. 50 (2014) 3735;

(c) C. Wang, T. Zhang and W. Lin, Chem. Rev. 112 (2012) 1084.

[4] (a) R.W. Saalfrank, I. Bernt, M.M. Chowdhury, F. Hammpel, G.B.M. Vaughan, Chem. Eur. J. 7 (2001) 2765;

(b) N. Matsumoto, Y. Motoda, T. Matsuo, T. Nakashima, N. Re, F. Dahan, J. P. Tuchagues, Inorg. Chem. 38 (1999) 1165;

(c) L. Pan, X.Y. Huang, J. Li, Y.G. Wu, N.W. Zheng, Angew. Chem., Int. Ed. 39 (2000) 527; 
(d) Dalgarno, S. J.; Hardie, M. J.; Raston, C. L. Cryst. Growth Des. 2004, 4, 227;

(e) Tong, M. L.; Hu, S.; Wang, J.; Kitagawa, S.; Ng, S. W. Cryst. Growth Des. 2005, 5, 837;

(f) G. Zhang, G. Yang, J. S. Ma, Cryst. Growth Des. 6 (2006) 1897-1902;

(g) K. A. Hirsch, S. R. Wilson, J. S. Moore, Chem. Eur. J. 3 (1997) 765;

(h) L. Carlucci, G. Ciani, P. Macchi, D.M. Proserpio, S. Rizzato, Chem. Eur. J. 5 (1999) 237;

(i) M.A. Withersby, A.J. Blake, N.R. Champness, P. Hubberstey, W.S. Li, M. Schröder, Angew. Chem., Int. Ed. Engl. 36 (1997) 2327.

(j) G.K. Batsala, V. Dokorou, N. Kourkoumelis, M.J. Manos, A.J. Tasiopoulos, T.

Mavromoustakos, M. Simčič, S. Golič-Grdadolnik, S.K. Hadjikakou, Inorg. Chim. Acta 382 (2012) 146.

[5] (a) J.-J. Liu, Y.-F. Guan, M.-J. Lin, C.-C. Huang, W.-X. Dai, Cryst. Growth Des. 16 (2016) 28361;

(b) E. Lee, K.-M. Park, M. Ikeda, S. Kuwahara, Y. Habata, S. S. Lee, Inorg. Chem. 54 (2015) 5372 ;

(c) E.W. Reinheimer, I. Hodzic, N.P. Rath, R.H. Groeneman, Polyhedron 98 (2015) 105;

(d) E. Lee, H. Ju, S. Kim, K.M. Park, S.S. Lee, Cryst. Growth Des. 15 (2015) 5427;

(e) J. McGinley, M. McCann, K. Ni, T. Tallon, K. Kavanagh, M. Devereux, X. Ma, V. McKe, Polyhedron, 55 (2013) 169;

(f) A.-Q. Ma, L.-G. Zhu, RSC Adv. 4 (2014) 14691.

[6] (a) M. Li, D. Li, O’Keeffe, O.M. Yaghi, Chem. Rev. 114 (2014) 1343;

(b) U.S. Schubert, A. Winter, G.R. Newkome, Terpyridine-Based Materials, Wiley-VCH, Weinheim, Germany 2011, Ch. 4;

(c) E.C. Constable, Chem. Soc. Rev. 36 (2007) 246;

(d) C. E. Housecroft, Dalton Trans. 43 (2014) 6594;

(e) G. Zhang, Y. Jia, W. Chen, W.-F. Lo, N. Brathwaite, J.A. Golen, A.L. Rheingold, RSC Adv. 5 (2015) 15870;

(f) Z. Yin, G. Zhang, T. Phoenix, S. Zheng, J.C. Fettinger, RSC Adv. 5 (2015) 36156.

[7] (a) A.J. Blake, N.R. Champness, S.M. Howdle, P.B. Webb, Inorg. Chem. 39 (2000) 1035;

(b) A.J. Blake, N.R. Champness, W. Levason, G. Reid, Inorg. Chem. 35 (1996) 4432;

(c) A.J. Blake, N.R. Champness, W. Levason, G. Reid, Chem. Commun. (1995) 1277;

(d) A.J. Blake, N.R. Champness, S.M. Howdle, K.S. Morley, P.B. Webb, C. Wilson, CrystEngComm 4 (2002) 88.

[8] (a) K. Li, Z. Xu, H. Xu, P.J. Carroll, J.C. Fettinger, Inorg. Chem. 45 (2006) 1032;

(b) X. Gan, M. Munakata, T. Kuroda-Sowa, M. Maekawa, Bull. Chem. Soc. Jpn. 67 (1994) 3009; 
(c) G. Huang, H. Xu, X.-P. Zhou, Z. Xu, K. Li, M. Zeller, A.D. Hunter, Cryst. Growth Des.7 (2007) 2542;

(d) M.B. Inoue, M. Inoue, M.A. Bruck, Q. Fernando, Chem. Commun. (1992) 515;

(e) J.C. Zhong, Y. Misaki, M. Munakata, T. Kuroda-Sowa, M. Maekawa, Y. Suenaga, H. Konaka, Inorg. Chem. 40 (2001) 7096.

[9] (a) D. Liao, J. Chen, H. Zhou, Y. Wang, Y. Li, C. Yu, Anal. Chem. 85 (2013) 2667;

(b) M.-L. Ho, C.-H. Shih, C.-H. Lee, G.-H. Lee, CrystEngComm, 13 (2011) 992;

(c) K.K. Bisht, A.C. Kathalikkattil, E. Suresh, RSC Adv. 2 (2012) 8421;

(d) M. Osawa, I. Kawata, R. Ishii, S. Igawa, M. Hashimotoab, M. Hoshino, J. Mater. Chem. C, 1 (2013) 4375;

(e) A. Spangenberg, J.-P. Malval, H.A. Kilig, J.-L. Fillaut, F. Stehlin, N. Hobeika, F.M. Savary, O. Soppera, Macromolecules 45 (2012) 1262.

[10] (a) H.P. Wu, C. Janiak, G. Rheinwald, H. Lang, J. Chem. Soc., Dalton Trans. (1999) 183;

(b) C. Janiak, L. Uehlin, H.P. Wu, P. Klüfers, H. Piotrowski, T.G. Scharmann, J. Chem. Soc., Dalton Trans. (1999) 3121.

[11] (a) X.-H. Bu, W.-F. Hou, M. Du, W. Chen, R.-H. Zhang, Cryst. Growth Des. 2 (2002) 303;

(b) J.R. Li, R.H. Zhang, X.H. Bu, Cryst. Growth Des. 3 (2003) 829;

(c) J.R. Li, X.H. Bu, J. Jiao, W.P. Du, X.H. Xu, R.H. Zhang, J. Chem. Soc., Dalton Trans. (2005) 464;

(d) M.O. Awaleh, A. Badia, F. Brisse, Inorg Chem. 44 (2005) 7833;

(e) M.O. Awaleh, A. Badia, F. Brisse, Cryst. Growth Des. 5 (2005) 1897;

(f) M.O. Awaleh, A. Badia, F. Brisse, X.H. Bu, Inorg. Chem. 45 (2006) 1560;

(g) M.O. Awaleh, A. Badia, F. Brisse, Cryst. Growth Des. 6 (2006) 2674;

(h) M.O. Awaleh, A. Badia, F. Brisse, Inorg. Chem. 46 (2007) 3185;

(i) M.O. Awaleh, A. Badia, F. Brisse, J. Chem. Crystallogr. 39 (2009) 122.

(j) M. O. Awaleh, F. Brisse ,Y. D. Soubaneh, T. Maris, Polyhedron 29 (2010) 2966.

[12] N.J. Korte, V.A. Stepanova, I.P. Smoliakova, J. Organomet. Chem. 745-746 (2013) 356-362.

[13] Mercury: Visualization and analysis of crystal structures. C.F. Macrae, P.R. Edgington, P. McCabe, E. Pidcock, G.P. Shields, R. Taylor, M. Towler, J. van de Streek, J. Appl. Crystallogr. 39 (2006) 453.

[14] V. A. Blatov, A. P. Shevchenko, TOPOS Professional v. 4.0, Samara State University, Russia, 1989-2008.

[15] Coordination Polymers: Design, Analysis and Application. S.R. Batten, S.M. Neville, D.R. 
Turner, 2008, RSC Publishing.

[16] (a) C.A. Kruithof, H.P. Dijkstra, M. Lutz, A.L. Spek, R.J. M. K. Gebbink, G. van Koten, Organometallics 27 (2008) 4928;

(b) A. Bockholt, P. Jutzi, A. Mix, B. Neumann, A. Stammler, H.-G. Stammler, Z. Anorg. Allg. Chem. 635 (2009) 1326.

(c) J. Aydin, K.S. Kumar, 1. Eriksson, K.J. Szabó, Adv. Synth. Catal. 349 (2007) 2585.

[17] (a) S. Liao, C.-Y. Su, H.-X. Zhang, J.-L. Lin, Z.-Y. Zhou, H.-Q. Liu, A.S.C. Chan, B.-S. Kang, Inorg. Chim. Acta 336 (2002) 151;

(b) L. Han, B. Wu, Y. Xu, M. Wu, Y. Gong, B. Lou, B. Chen, M. Hong, Inorg. Chim. Acta 358 (2005) 2005;

(c) R.M. Silva, M.D. Smith, J.R. Gardinier, Inorg. Chem. 45 (2002) 2132;

(d) H.-Z. Dong, H.-B. Zhu, X. Liu, S.-H. Gou, Polyhedron 27 (2008) 2167.

(e) A. Mizar, C. Pettinari, F. Marchetti, I. Timokhin, A. Crispini, Inorg. Chem. Commun. 24 (2012) 20;

(f) R.K. Mudsainiyan, A.K. Jassal, M. Arora, S.K. Chawla, J. Chem. Sci. 127 (2015) 849. 


\section{Graphic Abstract - Pictogram}

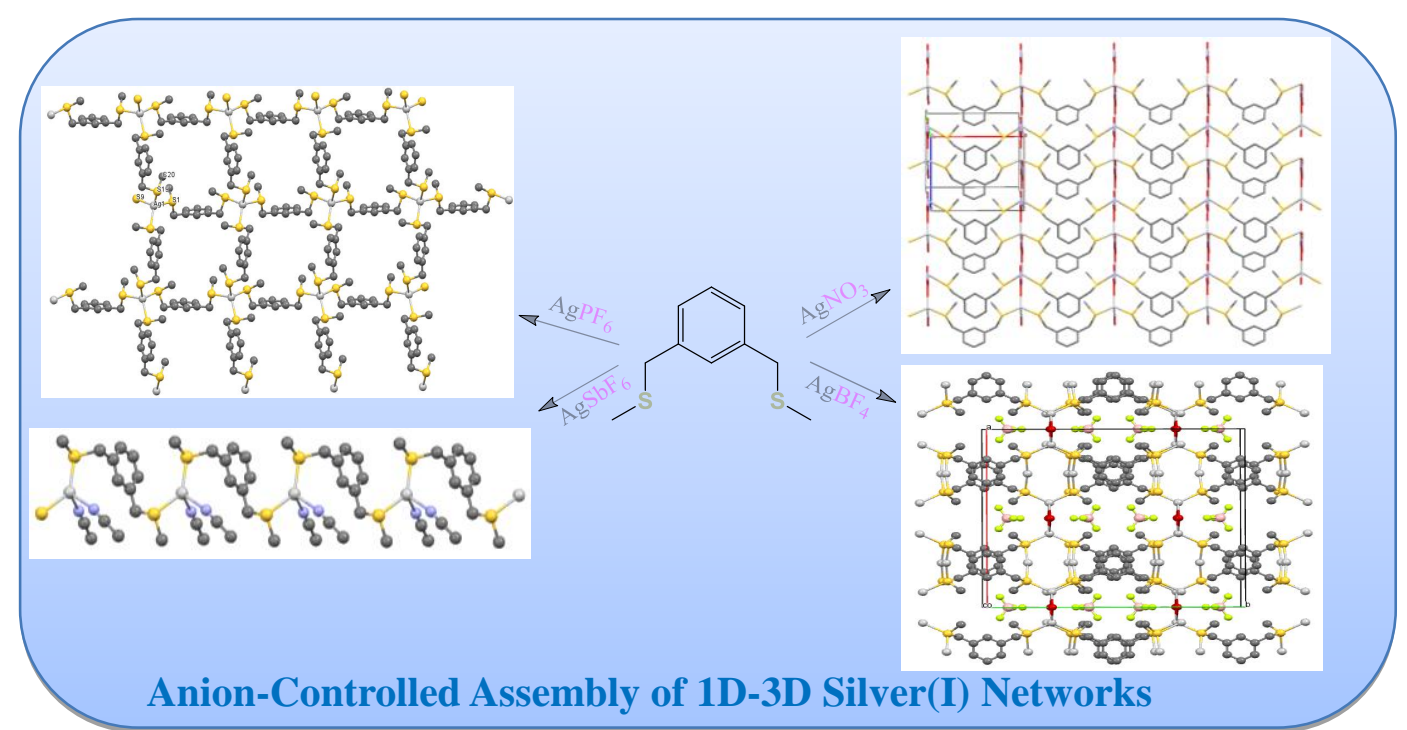




\section{Abstract - Synopsis}

Four new silver(I) coordination polymers based on a flexible thioether 1,3-

bis(methylthiomethyl)benzene have been synthesized and structurally characterized by X-

ray crystallography. The anion effect on the structural diversity of various silver(I)

networks was studied. 